\title{
ANÁLISE DA COMPATIBILIDADE ENTRE A INCLUSÃO DO ARTIGO 394-A NA CONSOLIDAÇÃO DAS LEIS TRABALHISTAS PELA LEI N. 13.467/2017 E A PROTEÇÃO INTERNACIONAL DA TRABALHADORA GESTANTE
}

\author{
Carolina Cammarosano Segnini ${ }^{72}$ \\ Raphael Varga Scorpião ${ }^{73}$
}

Recebido em: 29/04/2019 Aprovado em: 18/09/2019

\begin{abstract}
RESUMO
O artigo visa apontar como a Lei 13.467/2017 trouxe um grande retrocesso social no que se refere à temática dessa pesquisa, bem como afrontou princípios constitucionais e tratados internacionais de direitos humanos, ferindo a dignidade da pessoa humana. Isso porque, a permissão do labor da gestante em meio ambiente de trabalho insalubre, situação vedada pela Lei 13.287/2016, traz inúmeros riscos não só à trabalhadora, bem como nascituro/ criança. Desse modo, fezse uma abordagem histórica sobre o início das normas de direitos humanos no âmbito internacional e nacional até os dias atuais, utilizando-se de técnicas de pesquisas teóricas, com predominância de consulta às fontes jurídicas, como legislação, doutrinas e artigos jurídico-científicos.
\end{abstract}

Palavras-chave: Meio ambiente de trabalho. Gestante. Reforma Trabalhista.

\section{INTRODUÇÃO}

A presente pesquisa se propôs a fazer uma análise da Lei 13.467/2017, em especial da inclusão do artigo 394-A na Consolidação das Leis Trabalhistas, tendo como parâmetro normas internacionais de proteção dos direitos humanos, posto que as normas previstas nos parágrafos $2^{\circ}$ e $3^{\circ}$ do artigo $5^{\circ}$ da Constituição Federal ao mesmo tempo que garantiram uma

\footnotetext{
${ }^{72}$ Advogada trabalhista, graduada em Direito pela Universidade Católica de Santos, Especialista em Direito e Processo do Trabalho pela Escola Paulista de Direito, Mestranda em Direito Ambiental pela Universidade Católica de Santos.

${ }^{73}$ Analista do Ministério Público do Trabalho, graduado em Direito pela Universidade Estadual Paulista (UNESP), especialista em Direito Civil pela Pontifícia Universidade Católica de Minas Gerais (PUC-MINAS) e mestrando em Filosofia do Direito pela Pontifícia Universidade Católica de São Paulo (PUC-SP).
} 
abertura a normas protetivas à pessoa humana para além da Carta Constitucional, explicitou a força normativa dos textos convencionais anuídos pela República Federativa do Brasil.

Neste passo, o objetivo geral era contextualizar a Lei 13.467/2017 com as normas internacionais de direitos humanos, promovendo uma análise holística da ciência jurídica, transcendendo fronteiras políticas nacionais. Diante da hipercomplexidade da sociedade pósmoderna, as relações humanas e, portanto, jurídicas, não se limitam ao plano nacional, sendo certo que especialmente após o período de guerras na primeira metade do século $\mathrm{XX}$ a proteção dos direitos humanos passou a ser enxergada como de interesse de todas as nações. Formou-se em grande medida um consenso, por óbvio não uma unanimidade, de que o desprezo à humanidade visto no entreguerras seria um risco à própria continuidade da vida humana, formando-se e se desenvolvendo toda uma sistemática jurídica no cenário internacional e se estabelecendo Cortes Internacionais de solução de conflitos tanto no sistema onusiano, como em blocos regionais, a exemplo da Comissão e Corte Interamericana de Direitos Humanos, a primeira situada em Washington nos Estados Unidos da América e a segunda em São José na Costa Rica, isso para ficarmos apenas no universo da Organização dos Estados Americanos (OEA).

Especificamente, buscou-se verificar se a inclusão do artigo 394-A da Consolidação das Leis Trabalhistas, que disciplina o afastamento da trabalhadora gestante em grau máximo, médio e mínimo, exigindo-se neste dois últimos casos a apresentação de atestado médico pela própria trabalhadora que recomende o afastamento durante a gestação e/ou lactação é compatível com as convenções internacionais de direitos humanos aderidas voluntariamente pelo Brasil. Se a validade da norma necessita estar em consonância com a Constituição Federal, os parágrafos $2^{\circ}$ e $3^{\circ}$ do artigo $5^{\circ}$ do mesmo diploma alargam sobremaneira o bloco de parâmetro de análise de validade: a norma não apenas está sujeita a um controle de constitucionalidade, mas também a um controle de convencionalidade, o qual é feito por Órgãos jurisdicionais internacionais, mas também em âmbito local pelo julgador pátrio.

Para tanto adotou-se uma metodologia exploratória, analítica e crítica, como própria das ciências humanas, notadamente bibliográfica, aprofundando-se na doutrina absolutamente reconhecida e prestigiada no país e fora dele, além da jurisprudência do Supremo Tribunal Federal. A problemática da pesquisa girou em torno de um possível descompasso daquilo que se produziu em termos legislativos no plano interno a partir da Lei n. 13.467/2017 e o direito posto em tratados e convenções internacionais. A hipótese então seria demonstrar que a inclusão do artigo 394-A na Consolidação das Leis Trabalhistas estava em dissonância com a 
sistemática internacional de proteção à pessoa humana e a proibição ao retrocesso social, também chamado de efeito cliquet, e, desta forma, seria inconvencional e inconstitucional.

Como característica marcante dos direitos humanos, a historicidade ganha destaque. A proteção da pessoa humana faz parte de um processo histórico de ampliação, tendo sempre como norte a expansão dos direitos inerentes ao ser humano, a fim de que este goze de uma vida digna e plena, podendo explorar de maneira minimante satisfatória a suas potencialidades pautadas em seu projeto existencial. Se na antiguidade já se tem um esboço protetivo da condição humana tendo uma ideia primitiva de jusnaturalismo, é na idade média que surgem documentos disciplinando garantias fundamentais, como o remédio institucional habeas corpus, a limitação do poder do soberano e a positivação de valores atinentes a liberdades individuais.

Entretanto, os direitos humanos ganham um reconhecimento exponencial na segunda metade do século XX e passa a galgar um reconhecimento da comunidade internacional, a fim de que a experiência bélica vivenciada na primeira metade do século não fosse repetida. Como não poderia deixar de ser, é de rigor de um Estado Democrático de Direito a proteção do cidadão não apenas em face do próprio Estado, mas também em face de particulares que, diante da relação hierarquizada que ocupa, possa também vir a lesar direitos.

A partir do reconhecimento próprio da vulnerabilidade que possui o trabalhador, surgiram organizações internacionais destinadas à proteção do trabalho decente, impondo limites à relação laboral, fixando patamares rígidos na manutenção de um meio ambiente de trabalho sadio, salubre e alheio a agentes nocivos à saúde do trabalhador, como as centrais sindicais nos Estados Unidos da América e na França, além do advento da Organização Internacional do Trabalho (OIT).

Detalhado em um primeiro momento o direito do trabalho e a proteção internacional dos direitos humanos, passou-se à polêmica envolvendo a hierarquia dos tratados internacionais antes e depois da inclusão do parágrafo $3^{\circ}$ ao artigo $5^{\circ}$ na Constituição Federal. $\mathrm{O}$ artigo $5^{\circ}$, parágrafo $2^{\circ}$ da Carta Constitucional brasileira aduziu que os direitos ali previstos não excluem outros decorrentes do regime e dos princípios adotados, ou dos tratados internacionais em que a República Federativa do Brasil seja parte, levando à interpretação de que tanto as normas nacionais como internacionais relativas a direitos humanos formariam um grande bloco, cuja análise de constitucionalidade das normas deveria respeito e adequação.

Ocorre que o Supremo Tribunal Federal julgou o Recurso extraordinário nº 466.343 e, embora em decisão não unânime, deu interpretação diversa ao estatuir que as normas internacionais de direitos humanos possuem hierarquia infraconstitucional, porém supralegal, 
sendo dotadas de força paralisante de leis inferiores à Constituição Federal como é o caso aqui tratado (artigo 394-A da CLT, introduzido pela Lei n. 13.467/2017). Sendo assim, adotando a tese de que Convenções Internacionais possuem status constitucional ou adotando a posição prevalente no Supremo Tribunal Federal de supralegalidade, caso a conclusão seja pela incompatibilidade da reforma trabalhista com o ordenamento de jus cogens internacional, a norma interna não sustenta sua validade jurídica.

Evoluindo na investigação, a Organização Internacional do Trabalho estabelece como prioridade a tutela da trabalhadora gestante e seu filho ou filha, tanto que editou três convenções acerca da temática, sendo o Brasil signatário de duas delas (n.102 e n. 10), enquanto setenta e um países ratificaram ao menos uma das convenções protetivas à gestante. Tal número indica a preocupação da comunidade internacional em promover o trabalho decente a este grupo em especial situação de vulnerabilidade. As Convenções n. 183 e n. 191 da Organização Internacional do Trabalho reconhecem no âmbito internacional uma proteção especial no local de trabalho em que a gestante desempenha suas funções, além da eliminação de riscos; adaptação das condições de trabalho; transferência para uma função mais segura, sem perda de salário, quando esta adaptação não for possível, assim como da licença remunerada, se tal transferência foi impossível de ser realizada. O que se percebe é que a promoção de um trabalho decente, seguro e salubre é uma preocupação dos direitos humanos no plano global, especialmente se quem presta o trabalho é a mulher gestante.

A proteção interna do trabalho da gestante no Brasil, como não poderia deixar de ser, está intimamente relacionada à gradativa inclusão da mulher no mercado de trabalho. Já no início do século XX tem-se um movimento nacional a fim de disciplinar por meio de leis o trabalho feminino, atentando-se às características próprias deste gênero. No entanto, quando a Consolidação das Leis Trabalhistas entrou em vigor reuniu as leis esparsas vigentes à época sobre direito individual do trabalho, direito coletivo do trabalho e direito processual do trabalho. Na CLT, as regras de proteção do trabalho da mulher encontram-se previstas no Capítulo III do Título III, as quais dispõem sobre as normas especiais de tutela do trabalho feminino, sendo que as medidas de amparo à maternidade das empregadas figuram na Seção $\mathrm{V}$.

Da mesma forma, o constituinte de 1988 se manteve atento ao trabalho da mulher, estabelecendo proibições discriminatórias e trazendo a proteção da maternidade em seu bojo. Explorada todo este cenário normativo interno e internacional pode-se adentrar no texto do artigo 394-A da Consolidação das Leis Trabalhistas e da imposição feita por ele de que a gestante que trabalha sob graus de insalubridade médio e mínimo teria a incumbência de 
apresentar um atestado médico de profissional de sua confiança indicando que esta deve ser afastada da prática de trabalhos e/ou de ambientes nestes níveis de insalubridade.

É a partir de uma perspectiva internacional que a pesquisa se desenvolveu, analisando a complexidade da modificação legislativa brasileira em comparação ao que se produz juridicamente no quadro global, adentrando o texto de convenções e resoluções da OIT, de tratados onusianos e normas produzidas no âmbito regional da Organização dos Estados Americanos. Pensando a ciência do direito como algo que transcende fronteiras nacionais, o estudo se propôs a pensar a reforma trabalhista por um prisma global, posto que ao ampliar a lente de análise para o sistema internacional se tem uma maior fonte normativa, jurisprudencial e argumentativa.

Ao fim desta investigação, busca-se uma confirmação para a hipótese aventada e se rascunha uma interpretação normativa atenta aos ditames que fundamentam a dignidade humana e justifica a própria existência do direito, seja com ou sem limites geopolíticos.

\section{O DIREITO DO TRABALHO E A PROTEÇÃO INTERNACIONAL DOS DIREITOS HUMANOS}

Impende salientar que a doutrina não é unânime quanto ao surgimento dos direitos humanos, mas pode-se afirmar que o reconhecimento da existência de uma igualdade entre os homens decorrente do simples fato de sua humanidade, da sua superioridade em relação aos outros seres e da sua racionalidade, como dados iniciais para a construção do seu conceito. Este período, de acordo com COMPARATO (2001) é chamado de Axial e figurou entre os séculos 600 a 480 a.C.:

(...) é a partir do período axial que o ser humano passa a ser considerado, pela primeira vez na história, em sua igualdade essencial, como ser dotado de liberdade e razão, não obstante as múltiplas diferenças de sexo, raça, religião ou costumes sociais. Lançam-se, assim, os fundamentos intelectuais para a compreensão da pessoa humana e para a afirmação de direitos universais, porque a ela inerentes.

Tais direitos vieram de diversos ramos do conhecimento, desde a religião até a filosofia.

A justificativa que a existência de leis comuns que, independente de positivação, deveriam ser aplicadas a todos os homens, pelo fato de sua humanidade e de sua natureza comum, decorrente de um só Deus. Esta, a partir das ideias defendidas pelos sofistas e estoicos, justificava a existência de um "direito natural anterior e superior às leis escritas 
(MORAES, 1998). A perspectiva jusnaturalista trazia a ideia de direitos absolutas, imutáveis e inerentes aos seres humanos.

Em período posterior, já na Idade Média, Santo Tomás de Aquino (1226-1274) defendeu a ideia da existência de uma igualdade essencial da pessoa, independentemente do lugar que ela ocupa na sociedade, da sua cor ou religião, o que justifica a existência de direitos comuns a todos os homens. Ademais, nesse período foi realizado o primeiro documento com referência a direitos e liberdades civis clássico, garantindo a propriedade privada, o habeas corpus, a liberdade de locomoção e o devido processo legal.

Em 1215 surgiu a Magna Carta, através do rei João Sem- Terra e pelos bispos e barões ingleses, assegurando a liberdade e limitando o poder do soberano, o qual deveria respeitar os direitos subjetivos dos governadores. Nesse sentido, (COMPARATO, 2001) dispõe que a sua forma de promessa unilateral, feita pelo rei, ainda assim constitui uma convenção passada entre o monarca e os barões feudais, pela qual se lhes reconheciam certos foros, isto é, privilégios especiais. Afinal, ela previa como garantias e liberdades da igreja, proporção entre delito e pena, liberdade de locomoção, acesso à justiça, entre outros.

Desse modo, (MAGALHÃES, 2000) afirma que enquanto na Idade Média o Direito Natural era visto como vinculado à vontade de Deus, a partir da escola de Direito Natural de Grotius, em 1625, ele passa a ser fruto da razão.

Robustecendo as informações, frisa-se que no século XVII, as declarações de direitos inglesas, como é o caso do Bill of Rights ${ }^{74}$, foram elencados um rol de direitos e liberdades para o povo, tais como a proibição de impostos sem autorização do Parlamento e de penas cruéis, o princípio da legalidade penal e o direito de petição, além de limitar os poderes do monarca. A principal característica, por sua vez, foi a característica a divisão de poderes, a qual está estritamente conectada à proteção dos direitos fundamentais ligados à liberdade. Nesse sentido, (SARLET, 2009) expõe:

[...] as declarações inglesas do século XVII significaram a evolução das liberdades e privilégios estamentais medievais e corporativos para liberdades genéricas no plano do direito público, implicando expressiva ampliação, tanto no que diz com o conteúdo das liberdades reconhecidas, quanto no que toca à extensão da sua titularidade à totalidade dos cidadãos ingleses. (SARLET, 2009, p.43)

Apesar da Declaração de Independência dos Estados Unidos reafirmar os direitos humanos, foi na França que ocorreu a consagração normativa dos direitos fundamentais

\footnotetext{
${ }^{74}$ Bill of Rights: É a Declaração de Direitos elaborada pelo Parlamento da Inglaterra e imposta aos soberanos. É considerado um dos pilares do sistema constitucional do Reino Unido, pelo qual estabelece limites aos poderes do monarca e declara os direitos do Parlamento, incluindo regular deliberação parlamentar, eleições livres e liberdade de expressão no Parlamento
} 
através da Declaração dos Direitos do Homem e do Cidadão de 1789, que possuía maior conteúdo democrático e social e colocou fim ao absolutismo. Outrossim, COMPARATO, 2001 relata:

\begin{abstract}
As declarações de direitos norte-americanas, juntamente com a Declaração francesa de 1789, representaram a emancipação histórica do indivíduo perante os grupos sociais aos quais ele sempre se submeteu: a família, o clã, o estamento, as organizações religiosas. [...] Mas, em contrapartida, a perda da proteção familiar, estamental ou religiosa tornou o indivíduo muito mais vulnerável às vicissitudes da vida. A sociedade liberal ofereceu-lhe, em troca, a segurança da legalidade, com a garantia da igualdade de todos perante a lei.
\end{abstract}

Nessa esteira, nota-se que o modelo de trabalho antigo ligado à servidão e às corporações de ofício foram rompidos ao passo que a Revolução Industrial se instala, tendo como fonte propulsora a existência de trabalho livre. Assim, com o passar dos anos, o cenário econômico e social mudou bruscamente, construindo uma disparidade muito grande, em que um pequeno número de pessoas detinha poder e dinheiro enquanto a maioria vivia em condições precárias. Tal fato, rendeu vários movimentos sociais e de classe, na busca por condições de vida mais dignas, em especial, aqueles ligados aos trabalhadores.

A priori, é necessário destacar que a efetivação de um Estado Democrático de Direito pressupõe que os representantes dos seus Tribunais Superiores protejam ao máximo os direitos humanos, sejam eles positivados no plano interno ou no plano internacional. Atinente a este valor máximo a ser protegido e concretizado, os Tribunais nacionais devem buscar sempre prestar a tutela jurisdicional a fim de garantir que as normas protetoras da dignidade da pessoa humana sejam mais do que meras normas programáticas ou de conteúdo vazio, garantindo a força normativa da Constituição Federal, bem como dos Tratados e Convenções de Direitos Humanos anuídos pela República Federativa do Brasil. Essa medida pode representar uma profunda transformação na sociedade brasileira, uma vez que amplia as garantias dos cidadãos tanto frente ao Estado, como frente aos demais particulares, diante da eficácia horizontal dos direitos humanos.

Com o processo de internacionalização dos direitos humanos pós Segunda Guerra Mundial, temos o surgimento e posterior fortalecimento das Organizações Internacionais de proteção aos direitos humanos, seja no âmbito global com a Organização das Nações Unidas, seja no âmbito regional, como a Organização dos Estados Americanos. Na visão moderna, os direitos humanos podem ser conceituados como os direitos de todos sem qualquer tipo de discriminação, como cor, religião, nacionalidade, gênero, orientação sexual ou política, tendo em vista que, apesar de não serem absolutos, são àqueles fundamentais para a dignidade. Tais 
direitos são lançados a um patamar superior de atenção da comunidade internacional, a partir do momento em que são criados comitês, comissões e, posteriormente, cortes com o especial fim de julgar de maneira complementar casos de graves violações de direitos humanos, bem como exarar opiniões consultivas a respeito da interpretação de Tratados Internacionais de Direitos Humanos, como a Convenção Americana de Direitos Humanos e o Protocolo de San Salvador, os quais positivaram direitos chamados de segunda dimensão, como os sociais, econômicos e culturais.

Após o pós-guerra, os direitos humanos e o direito internacional atrelaram-se, estando a comunidade internacional, por meio de suas organizações globais ou regionais, cada vez mais tendentes a influenciar os estados soberanos na concretização dos direitos humanos e consequente tutela e efetivação dos direitos da cidadania, direito este que não encontra limites em soberania estatal ou decisão política de determinado governo. Se o Poder Judiciário é uma trincheira da busca por cidadania social, as Cortes internacionais constituem uma proteção a mais, ou seja, um novo horizonte ainda pouco pesquisado e trabalhado no ambiente acadêmico brasileiro.

No entanto, é pertinente mencionar que o Estado Democrático de Direito visa, por meio da garantia de direitos, alcançar a plenitude do ser humano, ou seja, assegurar pelas leis o mínimo necessário para que alguém explore suas potencialidades e desenvolva sua personalidade, para que possa sentir-se inserido, e hábil a viver com dignidade.

Neste sentido, as Organizações Internacionais ganham especial relevância, uma vez que elas constituem uma garantia a mais na proteção dos direitos humanos, responsabilizando os Estados por seus compromissos assumidos internacionalmente e negligenciados internamente, bem como fomentando a construção de conceitos jurídicos e entendimentos jurisprudências, os quais acabam por servir de norte para os Tribunais Constitucionais dos Estados independentes como é o caso do Supremo Tribunal Federal, bem como para Tribunais Superiores Infraconstitucionais, como o Superior Tribunal de Justiça.

Desse modo, os tratados internacionais de proteção dos direitos humanos, a um só tempo, afirmam a personalidade internacional do indivíduo, endossando a concepção universal dos direitos humanos e acarretam aos Estados que os ratificam obrigações no plano internacional. Se, no exercício de sua soberania, os Estados aceitam as obrigações jurídicas decorrentes de tratados de direitos humanos, passam então a se submeter à autoridade das instituições internacionais, no que diz respeito à tutela e fiscalização desses direitos em seu território. (PIOVESAN, 2016). 
Quanto ao direito do trabalho no cenário internacional, é deveras citar a influência das centrais sindicais da França, dos Estados Unidos e da Inglaterra na criação da Organização Internacional do Trabalho, pela Conferência da Paz (1919). Afinal, (SUSSEKIND, 2010) mal começara a Primeira Grande Guerra, a American Federation of Labor iniciou gestões junto a outras centrais sindicais, visando a que o futuro tratado de paz contivesse um estatuto sobre as normas de proteção ao trabalhador. Os dirigentes sindicais europeus, tendo à frente Leon Jouhaux, da CGT francesa, ampliaram a proposta da central norte-americana, reivindicando que delegados das organizações sindicais participassem da Conferência da Paz, ao lado dos representantes governamentais. Nesse interim, cumpre salientar o papel pioneiro da Constituição do México de 1917, ao inserir no seu texto algumas normas fundamentais da proteção ao trabalhador, que foram extremamente relevantes à época.

Diante do cenário daquela década, a legislação social-trabalhista nasceu intervencionista, pois ela limitava a autonomia da vontade nas relações de trabalho ou para instituir sistemas obrigatórios de previdências. Assim, na formação do Direito do Trabalho (SUSSEKIND, 2010) está intrinsicamente interligada com o liberal-individualismo da Revolução Francesa, ao socialismo utópico de Owen, ao Movimento Cartista e ao socialismo científico esteado no Manifesto Comunista de Marx e Engels, além da ação dos reformadores sociais, desenvolvida por intelectuais, sindicatos e Igreja Católica.

Verifica-se que houve cristalina finalidade em universalizar os princípios de justiça social e incrementar a cooperação internacional visando à melhoria das condições de vida do trabalhador, a fim de que em todo o planeta fosse estabelecido padrão mínimo de dignidade no exercício laboral. O fundamento da regulamentação internacional do trabalho reside na proteção dos trabalhadores em escala universal.

O próprio preâmbulo da Constituição da OIT já demonstra que a proteção do trabalhador não se restringe a um interesse individual, mas merece consideração por todas as nações, ao estabelecer que: “A não adoção, por uma nação qualquer, de um regime de trabalho realmente humano constitui obstáculo aos esforços de outras nações, que desejem melhorar a vida dos trabalhadores em seus próprios países".

Percebe-se que a defesa do trabalho decente e humanizado extrapola fronteiras políticas delimitadoras de países, se estendendo por onde quer que haja uma relação trabalhista. 


\section{A HIERARQUIA DOS TRATADOS INTERNACIONAIS DE DIREITOS HUMANOS}

Possivelmente, no que diz respeito à temática, a discussão do status hierárquico dos tratados internacionais de direitos humanos talvez seja o que causa mais divergência neste estudo aqui proposto.

$\mathrm{O}$ artigo $5^{\circ}$, em seu parágrafo $2^{\circ}$ consagrou uma abertura ao aduzir que os direitos ali previstos não excluem outros decorrentes do regime e dos princípios adotados, ou dos tratados internacionais em que a República Federativa do Brasil seja parte. Ao que parece da leitura do texto da norma, em havendo a incorporação, os direitos internacionais com a temática de direitos humanos receberiam uma natureza diferenciada, equivalente à norma constitucional. Nesta esteira, os direitos internacionais de proteção aos direitos humanos integrariam um bloco de constitucionalidade, ante o fato de serem materialmente constitucionais e diante da cláusula aberta que seria o supracitado parágrafo $2^{\circ}$, do artigo $5^{\circ}$ da Constituição Federal.

A doutrinadora Flávia Piovesan é entusiasta desse pensamento, entendendo que os direitos seriam organizados em três grupos: o dos direitos expressos na Constituição; o dos direitos expressos em tratados internacionais de que o Brasil seja parte; e, finalmente, o dos direitos implícitos, sendo que a Constituição de 1988 teria recepcionado os direitos enunciados em tratados internacionais de que o Brasil é parte, conferindo natureza constitucional a eles. (PIOVESAN, 2016).

Neste mesmo sentido, Carlos Weis reconhece a materialidade constitucional dos tratados de direitos humanos, que, diante de sua essência e valor não poderiam estar abaixo do nível constitucional, mas que não se fundem formalmente com a própria Constituição Federal. Desta forma coexistiriam dois sistemas normativos paralelos, ambos vigentes no país, mas com mecanismos próprios e estanques de criação, modificação ou extinção de suas previsões. Como sistemas jurídicos paralelos, ambos gerariam direitos subjetivos para pessoas submetidas à soberania brasileira. (WEIS, 2014).

Ocorre que, em dezembro de 2008, o Supremo Tribunal Federal julgou o Recurso extraordinário $\mathrm{n}^{\circ} 466.343$, decidindo pela proibição da prisão civil por dívida à hipótese de alienação fiduciária em garantia, fundamentando na Convenção Americana de Direitos Humanos. Em que pese o julgamento tenha se dado por unanimidade, divergiram os ministros em relação à hierarquia a ser atribuída aos tratados de direitos humanos, sendo que os ministros Celso de Mello, Cesar Peluso, Ellen Gracie e Eros Grau julgaram pelo status constitucional aos tratados de direitos humanos, ao passo que os demais ministros e, portanto, 
a tese vencedora, votaram no sentido de que tais tratados recebam um regime diferenciado, distinto dos demais tratados. Ficou decidido pelo Supremo Tribunal Federal que os tratados que envolvam direitos humanos possuem a hierarquia de normas supralegais, ou seja, normas infraconstitucionais, porém com status superior às demais normas.

Desta forma, para o Supremo Tribunal Federal, a internalização no ordenamento jurídico tem a força paralisante da eficácia jurídica de qualquer norma infraconstitucional que com ela colida.

Independente da tese adotada, a Consolidação das Leis Trabalhistas, por óbvio, possui caráter infralegal e, portanto, caso divirja de tratados internacionais de direitos humanos, terá sua eficácia por eles paralisada.

\section{A PROTEÇÃO INTERNACIONAL DA TRABALHADORA GESTANTE}

A Organização Internacional do Trabalho elenca a proteção à maternidade como uma questão central da organização desde a sua criação, cujo objetivo é proteger a saúde da mãe e de seu filho ou filha, além de resguardar a trabalhadora face a qualquer tipo de discriminação baseada na condição de mãe.

Foram adotadas três convenções da OIT sobre a proteção à maternidade: a número 3 , no ano de 1919; a número 103, no ano de 1952 e a número 183 no ano de 2000. Ademais, a de número 102, que se debruça sobre a seguridade social, reconhece as prestações de maternidade como uma das nove áreas de proteção social, prevendo assistência médica e pagamentos periódicos para compensar a suspensão de ganhos em razão da maternidade.

Pode-se dizer, com tranquilidade, que há um consenso da comunidade internacional em dar relevância à proteção da gestante, uma vez que setenta e um países ratificaram ao menos uma das convenções acerca do assunto, sendo que o Brasil é signatário das Convenções $n^{\circ} 102$ e n ${ }^{\circ} 103$.

Em se tratando de licença maternidade, a Convenção n ${ }^{\circ} 183$ estende o período de licença para o mínimo de catorze semanas, enquanto as anteriores estabeleciam doze. Já a Recomendação $\mathrm{n}^{\circ} 191$ sugere que esse período seja dilatado para dezoito semanas, ao passo que a Convenção $n^{\circ} 183$ garante uma licença adicional no caso de doença, complicações ou riscos relacionados à gravidez, prevendo ainda uma licença pós-parto obrigatória de seis semanas. Percebe-se uma tendência na dilação de prazos de licença, garantindo um contato 
maior entre mãe e filho ou filha e um regresso menos abrupto da mulher ao mundo do trabalho, com vistas claras à preservação de sua saúde e do contato com a criança.

Interessante a solução dada pela legislação trabalhista francesa quanto ao assunto. Caso seja o primeiro filho, é assegurada licença de seis semanas anteriores ao parto e dez semanas posteriores. Caso seja mão de dois ou mais filhos, afasta-se a mãe oito semanas antes do parto e dezoito após, uma vez que a mulher necessita se dedicar não apenas ao bebê, mas também aos demais filhos. Na hipótese de nascimento de gêmeos, há doze semanas anteriores ao parto e mais vinte e duas após o nascimento, enquanto para trigêmeos são vinte e quatro antes do parto e as mesmas vinte e duas após.

A Convenção $n^{\circ} 183$ da Organização Internacional do Trabalho reconhece no âmbito internacional uma proteção especial no local de trabalho em que a gestante desempenha suas funções, ao afirmar em seu artigo $3^{\circ}$ que os países-membros devem adotar as medidas necessárias para garantir que gestantes ou lactantes não sejam obrigadas a desempenhar um trabalho que seja prejudicial à sua saúde ou à saúde do seu filho ou filha ou cuja natureza implique um risco significativo.

No mesmo escopo protetivo a Recomendação no 191 prevê a adaptação das condições de trabalho das gestantes ou lactantes por meio de eliminação de riscos; adaptação das condições de trabalho; transferência para uma função mais segura, em perda de salário, quando esta adaptação não for possível, além da licença remunerada, se tal transferência foi impossível de ser realizada.

Também foi digna de proteção pela Convenção nº 183 o direito à amamentação, ao estabelecer que a mulher tem direito a uma ou várias interrupções por dia ou a uma redução diária na sua jornada de trabalho para amamentação, contabilizando essas interrupções na jornada de trabalho.

A Convenção sobre a Eliminação de Todas as Formas de Discriminação contra a Mulher, ratificada e incorporada ao ordenamento brasileiro, também tutela a gestante no meio ambiente de trabalho, ao estabelecer em seu artigo 11 o direito à proteção da saúde e à segurança nas condições de trabalho, inclusive a salvaguarda da função de reprodução; ao proibir a demissão por motivo de gravidez ou licença maternidade; além de determinar que é dever dar proteção especial às mulheres durante a gravidez nos tipos de trabalho comprovadamente prejudiciais para elas.

Ou seja, no sistema onusiano há toda uma normatização de proteção à gestante e sua filha ou filho, com especial atenção às peculiaridades que uma gestação possui. Não se pode 
falar em alcançar um padrão civilizatório minimamente razoável sem que se estabeleça um ambiente laboral saudável e uma prática empresarial inclusiva e não discriminatória.

Em relação ao sistema interamericano, a proteção social do trabalho digno também mereceu cuidado. O protocolo adicional à Convenção Americana sobre direitos humanos em matéria de direitos econômicos, sociais e culturais, nomeado de protocolo de San Salvador, em seu artigo $6^{\circ}$ estabelece o compromisso dos Estados com o direito ao trabalho, inclusive determinando que estes estabeleçam e executem programas que coadjuvem um adequado atendimento da família, a fim de que a mulher tenha real possibilidade de exercer o direito ao trabalho.

Da mesma forma que as Convenções da Organização Internacional do Trabalho, o Protocolo de San Salvador assegura a licença maternidade para a gestante, não apenas após o parto, como também antes dele.

\section{O HISTÓRICO DO TRABALHO DA GESTANTE NO BRASIL}

É sabido que o ingresso da mulher no mercado de trabalho ocorreu com a Revolução Industrial e Francesa, diante da necessidade de complementação de renda familiar. O processo de inclusão da mulher no mundo do trabalho, ao longo dos anos, vem seguida de elevada discriminação, não só em relação à qualidade de ocupações que têm sido criadas, seja no setor formal como no informal, mas no que se refere à desigualdade de remuneração entre homens e mulheres (MAIA, 2004).

A crescente presença das mulheres no mercado de trabalho a partir dos anos de 1970 e a sua permanência foi caracterizada pelo elevado nível de desemprego e crise econômica, como por exemplo o ano de 1980. No entanto, essas mesmas pesquisas salientavam que essa inserção se destacava pelas grandes diferenças salariais e pela elevada concentração em setores ligados ao comércio e a serviços, notadamente nas áreas de serviços sociais, trabalho doméstico e nas ocupações mais vulneráveis e de reduzida exigência de qualificação profissional. Essas características acompanham toda a trajetória de inserção das mulheres no mundo produtivo e tem suas raízes na desigual divisão sexual do trabalho e na atribuição às mulheres do trabalho reprodutivo.

O Brasil, desde o fim de escravidão, sofreu um grande déficit de mão de obra no campo, incentivando uma imigração europeia, tendo em vista a concessão de benefícios aos 
trabalhadores que viessem laborar na área rural, principalmente nas fazendas de café, as quais estavam em ascensão na época.

Nesse sentido, Carlos Bernardo Vainer ressalta "as duríssimas condições impostas aos imigrantes pelos contratos de parceria e a prepotência dos fazendeiros não tardariam a provocar reclamações, deserções, greves e verdadeiras revoltas.” (VAINER, 2000).

Considerando tal situação, muitos trabalhadores decidiram migrar para as cidades, coincidindo com o início da industrialização no Brasil, ocasionando transformações significativas na esfera laboral. Importante salientar as péssimas condições de trabalho, que fizeram surgir os primeiros sinais no país de movimentos reivindicatórios da classe trabalhadora.

Decerto, o trabalho da mulher nesse período não detinha grande notoriedade, eis que era voltado ao comércio de alimentos, como bolos, frutos, doces, entre outros. No entanto, a industrializou potencializou a inclusão da mulher nesse setor, principalmente nas indústrias têxteis (fiação e tecelagem).

Com isso, em 1912, começou a tramitar o primeiro projeto no Congresso Nacional, que tinha como um dos objetivos regular o trabalho feminino, estabelecendo que a mulher poderia:

[...] contratar emprego independentemente de autorização do marido, que lhe era vedado o trabalho noturno, que a jornada de trabalho não poderia exceder de 8 horas e que se poderia licenciar de 15 a 25 dias antes do parto e até 25 dias depois, com garantia de retorno ao emprego e percepção de um terço do salário no primeiro período e metade no segundo. (VIANNA, 2005, p. 979).

Por óbvio, o projeto foi rejeitado, diante das ideias conservadoras daquela época. Todavia, em âmbito estadual, a Lei n. 1.596/1917, no seu artigo 95, proibiu o trabalho das mulheres durante o último mês de gravidez e o primeiro do puerpério nos estabelecimentos industriais. (BARROS, 1995). Já na esfera federal, o Decreto n. 16.300/1923, aprovou o Regulamento do Departamento Nacional de Saúde Pública, tendo sido a primeira norma a facultar às mulheres que trabalhavam em estabelecimentos comerciais e industriais, repouso de trinta dias antes e trinta dias depois do parto (BARROS, 1995).

Esse diploma legal, em seu artigo 348, também previa que tais estabelecimentos facultassem às empregadas ou operárias que estivessem amamentando os filhos "o ensejo necessário ao cumprimento desse dever" (BRASIL, 1923). O Decreto 16.300/1923 fixava, ainda, em seu artigo 349, a organização de "caixas a favor das mães pobres" e, com o intuito de proteger as crianças, a criação de creches ou salas de amamentação localizadas próximas da sede das empresas ou indústrias para que as mães, duas ou três vezes durante a jornada 
laboral, pudessem amamentar seus filhos. No entanto, não estabelecia a duração desses intervalos.

O Decreto 21.417-A, de 17/05/1932 regulamentou as condições de trabalho das mulheres nos estabelecimentos industriais e comerciais, estabelecendo, em seu artigo $1^{\circ}$, que a todo trabalho de igual valor corresponderia salário igual, sem distinção de sexo. Tal Decreto previa muitos direitos às grávidas, como por exemplo o seu artigo $7^{\circ}$, que proibia o trabalho da mulher gestante, durante um período de quatro semanas, antes do parto, e quatro semanas depois, sendo que esses lapsos temporais poderiam ser aumentados até duas semanas cada um, em casos excepcionais, comprovados por atestados médicos. Ademais, ele também garantia à mulher trabalhadora, durante o período de afastamento que antecedia e sucedia o parto, um auxilio correspondente à metade dos seus salários, partindo da média dos seus últimos meses, pago pelas Caixas criadas pelo Instituto de Seguridade Social e, na falta dessas, pelo empregador.

Partindo dessa premissa, verifica-se que até 1934, somente as Normas infraconstitucionais cuidavam da situação da mulher trabalhadora, uma vez que a Constituição do Império nunca se manifestou acerca de tal matéria.

Nota-se que a Constituição de 1934 tratou da ordem econômica e social, tendo no seu $\S$ $1^{\circ}$ do artigo 121, assegurada a igualdade de salário entre homens e mulheres, proibindo o trabalho feminino em ambientes insalubres, garantindo a assistência médica e sanitária à gestante e concedendo-lhe descanso antes e depois do parto, sem prejuízo do salário e do emprego (BRASIL, 1934). O artigo 141 da mesma Constituição ainda tornou obrigatório, em todo o território nacional, o amparo à maternidade e à infância, motivo pelo qual a União, os Estados e os Municípios ficaram obrigada a destinar $1 \%$ das respectivas rendas tributárias para garantir a efetividade de tais proteção (BRASIL, 1934).

Constata-se que até o início da década de 40, várias normas legais trabalhistas foram editadas para atender condições específicas. Essa situação mudou quando a CLT entrou em vigor, pois reuniu todas as leis esparsas vigentes à época sobre direito individual do trabalho, direito coletivo do trabalho e direito processual do trabalho. Na CLT, as regras de proteção do trabalho da mulher encontram-se previstas no Capítulo III do Título III, as quais dispõem sobre as normas especiais de tutela do trabalho feminino, sendo que as medidas de amparo à maternidade das empregadas figuram na Seção V.

A fortiori, com a CLT, as normas de proteção à maternidade impuseram um ônus ao empregador, porquanto cabia a este pagar à empregada os salários integrais durante as seis semanas anteriores e posteriores ao parto, conforme artigo 393, contrariando o disposto na 
Convenção n. 3 da OIT, que atribuía tal encargo ao seguro social ou aos cofres públicos. (BARROS, 1995). O ônus imposto ao empregador de ser responsável pelo pagamento dos salários devidos à empregada durante o período de licença-maternidade, encareceu o custo da mão de obra feminina e, em consequência, gerou discriminação das mulheres no mercado de trabalho.

Visando impedir a discriminação das mulheres no concorrido mercado de trabalho, o Decreto 75.207/1975, o qual regulamentou a Lei 6.136/1974, em observância à Convenção n. 103 da OIT, ratificada pelo Brasil em 1952, transferiu o custo do salário-maternidade para a Previdência Social (BARROS, 1995). Desse modo, a partir de 1974, o salário-maternidade deixou de ser obrigação dos empregadores e passou a constituir prestação previdenciária. Posteriormente, a Lei 6.332, de 18/05/1976, deu nova redação ao artigo $2^{\circ}$ da lei mencionada no parágrafo anterior.

A atual Constituição, que estabelece serem fundamentos da República Federativa do Brasil, além de outros, a dignidade da pessoa humana e os valores sociais do trabalho e da livre iniciativa (artigo $1^{\circ}$, III e IV), preconiza, no inciso I do seu artigo $5^{\circ}$, que homens e mulheres são iguais em direitos e obrigações. Além disso, em seu artigo $7^{\circ}$, inciso $\mathrm{XXX}$, proíbe diferença de salários, de exercício de funções e de critério de admissão por motivo de sexo, idade, cor ou estado civil (BRASIL, 1988). Em relação às trabalhadoras gestantes, sejam elas, urbanas, rurais, domésticas ou avulsas, a CRFB/88, estendeu a licençamaternidade, antes de 84 dias, para 120 dias, "sem prejuízo do emprego e do salário", conforme prevê o inciso XVIII de seu artigo $7^{\circ}$.

Por seu turno, a alínea "b" do inciso II do artigo 10 do Ato das Disposições Constitucionais Transitórias (ADCT) veda a dispensa arbitrária ou sem justa causa da empregada gestante, desde a confirmação da gravidez até cinco meses após o parto. No entanto, com base na igualdade de tratamento entre homens e mulheres, a Carta Magna de 88, ao contrário do que prescreviam as Constituições de 1934, 1937, 1946 e 1967, não proíbe o trabalho das mulheres em ambientes insalubres. Em observância ao princípio da igualdade de gênero, a Lei 7.855, de 24/10/1989, revogou vários dispositivos da CLT, dentre eles, o artigo 387, que proibia o trabalho da mulher nos subterrâneos, nas minerações em subsolo, nas pedreiras e obras, de construção pública ou particular, e também nas atividades perigosas ou insalubres (RIBEIRO, 2009, p. 28). Portanto, desde outubro/1989, o trabalho em condições insalubres ou perigosas deixou de ser vedado à mulher.

Muito embora a atual Constituição, em seu artigo $7^{\circ}$, inciso $\mathrm{XX}$, estabeleça ser direito das trabalhadoras urbanas e rurais, a proteção do mercado de trabalho da mulher, mediante 
incentivos específicos, nos termos da lei, decorridos quase vinte e nove anos de vigência do texto constitucional, percebe-se, claramente, que o trabalho feminino não vem sendo alvo de muita preocupação por parte dos legisladores. Isso porque, poucas normas legais cumpriram esse objetivo. A Lei 9.029/1995, elimina e proíbe a exigência de atestados de gravidez e esterilização para admissão das mulheres ao emprego ou para a permanência da relação jurídica de trabalho.

A Lei 9.799, de 26/05/1999, inseriu na CLT regras sobre o acesso da mulher ao mercado de trabalho, com a adoção de medidas que visem ao estabelecimento das políticas de igualdade entre homens e mulheres, em particular as que se destinam a corrigir as distorções que afetam a formação profissional, o acesso ao emprego e as condições gerais de trabalho da mulher. O último diploma legal citado também é responsável por inserir dispositivo que trata da proteção à maternidade, garantindo à empregada, durante a gravidez, sem prejuízo do salário e demais direitos: i) transferência de função, quando as condições de saúde o exigirem, assegurada a retomada da função anteriormente exercida, logo após o retorno ao trabalho; ii) dispensa do horário de trabalho pelo tempo necessário para a realização de, no mínimo, seis consultas médicas e demais exames complementares. No entanto, a Emenda Constitucional n. 20/1998, sem se importar com a proteção à maternidade, que deve ser garantida às empregadas, fixou, em seu artigo 14, como limite máximo para o valor dos benefícios do regime geral de previdência social, dentre eles, o salário-maternidade, a importância de $\mathrm{R} \$ 1.200,00$ reajustada de forma a preservar, em caráter permanente, seu valor real.

Com o olhar voltado à saúde das futuras gerações, considerando que as condições no ambiente de trabalho podem prejudicar à saúde da gestante e de seu bebê, há pouco mais de um ano, a Lei 13.287, de 11/05/2016, acrescentou à CLT o artigo 394-A, determinando o afastamento da empregada gestante ou lactante de quaisquer atividades, operações ou locais insalubre, devendo exercer suas atividades em recinto salubre durante a gravidez ou a lactação.

Contudo, é indubitável que a maternidade, infelizmente, é motivo de discriminação para o acesso e a permanência da mulher no mercado de trabalho, constituindo-se em obstáculo para a promoção da igualdade de gênero e de oportunidade de tratamento no emprego. $\mathrm{O}$ Brasil, na condição de país-membro da OIT e signatário da Convenção n. 103 da OIT, vem adotando medidas para garantir que a nobre função de ser mãe não resulte em discriminação. No entanto, os mecanismos implementados para tal fim mostram-se incompletos, incapazes de combater efetivamente essa discriminação. Isso acontece com a previsão contida no artigo 394-A da CLT, conforme será visto a seguir. 


\title{
6 A REFORMA TRABALHISTA E A INCLUSÃO DO ARTIGO 394-A DA CLT.
}

O ponto chave da questão aqui suscitada não é só o perigo instaurado no meio ambiente de trabalho da gestante, mas também o ameaça da saúde do nascituro. Desse modo, não se trata apenas do direito ao livre exercício da profissão, mas também da proteção do feito que está desenvolvimento. Assim, cabe ao Estado proteger em todas as fases o desenvolvimento humano, que é o gestacional.

Assim, de acordo com (JUNIOR, 2013):

\begin{abstract}
"O florescimento do direito à saúde do trabalhador é consequência da valorização do trabalho, como objeto de tutela jurídica. A elevação do trabalho enquanto valor a ser defendido por toda sociedade é refletida na produção legislativa, na interpretação das leis, conciliando o mundo do direito com a realidade fática a ele subjacente".
\end{abstract}

Corroborando com essa problemática, um estudo realizado em colaboração com National Board of Health and Welfare, the Swedish Social Insurance Agency, and Statistics Sweden, na Suécia, em mais de 1,4 milhões de recém-nascidos, no período de 1986 a 2008, em que foi considerada a ocupação das mães, hábitos, idade, etnia, licença maternidade e fatores socioeconômicos, concluiu-se que as mães que se submetem a trabalhos ruidosos têm aumentadas em $80 \%$ a chance de a criança ter a sua audição prejudicada, total ou parcialmente.

É cristalino que a Lei n. 13.467/2017 surgiu em um momento conturbado no país, tendo em vista a crise econômica e troca de presidente. É inegável, portanto, que tal lei é uma afronta a todo conjunto de direitos sociais debatidos até o presente momento em nosso sistema constitucional e acolhido pela CLT. Todavia é indiscutível que o sistema jurídico não pode ficar estagnado com as reorganizações econômicas, sociais e culturais que o País enfrenta cotidianamente.

Nesse sentido, Vólia Bomfim, auxilia na concepção dos direitos suprimidos pela reforma trabalhista:

O conteúdo do Projeto de Lei, ao contrário do afirmado pela imprensa, desconstrói o Direito do Trabalho como conhecemos, inverte seus princípios, suprime regras favoráveis ao trabalhador, prioriza a norma menos favorável ao empregado, a livre autonomia da vontade, o negociado sobre o legislado (para reduzir direitos trabalhistas), valoriza a imprevisibilidade do trabalho, a liberdade de ajuste, exclui regras protetoras de direito civil e de processo civil ao direito e processo do trabalho. 
Ocorre que, no período que a gestante ou a lactante está realocada em um novo ambiente de trabalho salubre, a mesma perde o direito do recebimento de adicional de insalubridade, visto que o referido adicional tem ligação direta com a exposição aos agentes nocivos à saúde. Outrossim, caso a trabalhadora não estando exposta ao risco no ambiente de trabalho, não persistiria o risco social, razão pela qual não haveria a necessidade de permanência do pagamento de adicional de insalubridade.

Cabe reforçar a ideia de que a utilização de fundamentos baseados no prejuízo financeiro da gestante, não deve nunca prevalecer, pois o não acolhimento à proteção da mãe e do feto vai de encontro a todos os princípios relacionados aos direitos humanos, ao trabalho decente, às normas de proteção ambiental do trabalhador, aos pleitos dos órgãos internacionais, como a OIT e a Organização Mundial da Saúde (OMS).

Outrossim, em análise preliminar, nota-se que o rumo que havia sido trilhado pelo Brasil era de avanço social, dando preferência a um desenvolvimento econômico, e não a um mero crescimento econômico, afirmando uma evolução pautada na sustentabilidade econômica, social e cultural, onde além de preservar as conquistas já alcançadas, busca-se o progresso no caminho de uma maior dignidade e oportunidades nos diversos setores da sociedade.

Afinal, a meta de um direito conquistado, principalmente no que tocante aos direitos sociais, deve estar em consonância com o avanço em direção ao futuro e em distanciamento da situação pretérita de não garantia. Ou seja, a ordem positiva dos direitos deve assegurar, em sua evolução, a permanência dos direitos já assegurados, bem como o incremento das garantias dos cidadãos, de modo a se constituir busca incessante pela melhoria das condições fornecidas às pessoas tuteladas por essa ordem jurídica.

Isso porque, a finalidade de salvaguardar os direitos da gestante e a do feto que está sendo gerado é estimável e valoroso, para a proteção da saúde do infante, todavia, é importante atentar-se que nem todas as mulheres conseguirão desfrutar do direito que a lei as ampara sem que haja prejuízo, financeiros e morais

\section{CONSIDERAÇÕES FINAIS}

É notório que a formação histórica do Direito do Trabalho evidenciou um interesse na internacionalização das suas normas, criando inclusive a Organização Internacional do Trabalho. Desde então, o Direito Internacional não mais se limitou a prever acerca das 
relações exteriores dos Estados, vez que as normas adotadas pela Assembleia Geral da OIT sempre tiveram por destino sua incorporação ao direito interno dos Estados que a ela aderiram. Tal inovação estendeu-se, após a $2^{\mathrm{a}}$ Guerra Mundial, a outros organismos internacionais, sobretudo no sistema das Nações Unidas, para alcançar os direitos humanos e, especialmente, a educação, saúde e alimentação. Ou seja, ao lado do Direito Internacional clássico, nascia também o direito comum da humanidade.

Partindo do embasamento teórico exposto, percorrendo pela trajetória histórica do trabalho da mulher no Brasil e no mundo, sob o prisma do retrocesso social e do mínimo existencial, fica clara a confirmação da hipótese levantada, ou seja, que de fato houve um retrocesso social e uma consequente inconstitucionalidade e inconvencionalidade do artigo 394- A da CLT, já que além de regredir na questão da proteção social fundamental, o embasamento utilizado como motivo para a alteração legislativa não condiz com a realidade.

Nesse sentido, tal dispositivo além de ter ocasionado um retrocesso, corrobora o problema da discriminação da mulher no ambiente de trabalho. No entanto, confirma-se que a situação do meio ambiente laboral é um ponto de preocupação da sociedade, devendo as políticas públicas se voltarem a uma possível melhoria, sem pensar eminentemente em questões financeiras ou econômicas que cercam essa problemática.

É nesse sentido que se posiciona (CANOTILHO, 2003):

\begin{abstract}
"A ideia aqui expressa também tem sido designada como proibição de "contrarevolução social" ou da "evolução reaccionária". Com isto quer dizer-se que os direitos sociais e econômicos (ex.: direitos dos trabalhadores, direito à assistência, direito à educação), uma vez alcançados ou conquistados, passam a constituir, simultaneamente, uma garantia institucional e um direito subjetivo. A proibição de retrocesso social nada pode fazer contra as recessões e crises econômicas (reversibilidade fática), mas o princípio em análise limita a reversibilidade dos direitos adquiridos [...], em clara violação do princípio da proteção da confiança e da segurança dos cidadãos no âmbito econômico, social e cultural, e do núcleo essencial da existência mínima inerente ao respeito pela dignidade da pessoa humana. $\mathrm{O}$ reconhecimento desta proteção de direitos prestacionais de propriedade, subjetivamente adquiridos, constitui um limite jurídico do legislador e, ao mesmo tempo, uma obrigação de prossecução de uma política congruente com os direitos 65 concretos e as expectativas subjectivamente alicerçadas. A violação do núcleo essencial efetivado justificará a sanção de inconstitucionalidade relativamente a normas manifestamente aniquiladoras da chamada justiça social”.
\end{abstract}

O trabalho também verifica que a situação do meio ambiente laboral, em especial os insalubres ainda são uma preocupação da sociedade, devendo as políticas públicas aperfeiçoar esse cenário e não pensar só nas questões financeiras e econômicas que envolvem a problemática. Afinal, o princípio da dignidade da pessoa humana é um dos grandes princípios vetores em nosso ordenamento jurídico, e conforme mencionamos, a qualidade e a segurança 
ambiental são complementos ao referido princípio constitucional, podendo, do mesmo modo, concluir que o meio ambiente do trabalho se enquadra ao referido liame.

Corroborando com o entendimento, assim de pronuncia (BARCELLOS, 2011):

\begin{abstract}
"Não se trata, é bom observar, da substituição de uma forma de atingir o fim constitucional por outra, que o novo legislativo entenda mais apropriada. A questão que se põe é a da revogação pura e simples da disposição infraconstitucional por meio da qual o legislador esvazia o comando constitucional, exatamente como se dispusesse contra ele diretamente, daí por que as consequência hão de ser as mesmas nos dois casos. De toda sorte, também aqui, a eficácia jurídica só alcança as violações comissivas da norma, restando as omissivas, ainda uma vez, sem tutela própria".
\end{abstract}

Ao Estado, como guardião dos direitos fundamentais, impelido pela proibição de proteção deficiente a esse núcleo mínimo garantidor de dignidade e às conquistas já alcançadas em tal âmbito, cabe, portanto, a atuação no sentido de "evitar riscos para o cidadão em geral mediante a adoção de medidas de proteção ou de prevenção" (MENDES; BRANCO, 2013). Dentre essas medidas, por óbvio, se enquadram as medidas legislativas, que também devem sempre buscar a ampliação do espectro de garantias sociais e materiais do cidadão, nunca o seu retrocesso, tanto mais quando essa retroação atinge núcleo essencial de direito componente do chamado mínimo existencial.

Ao mesmo tempo, como já analisado, a atenção com a maternidade é de grande importância não só para a mulher gestante, e sim para toda a sociedade, estabelecendo seguranças jurídicas a essas mulheres trabalhadoras, estar-se-á assegurando às futuras gerações. Portanto, a conservação das normas atinentes ao tema relacionado à proteção da mulher é de extrema relevância, assim como deveriam ser tratadas com a devida importância desde as legislações anteriores, pois sua suspensão protetivas de tais direitos constituiria uma grande retrocessão social às garantias conquistadas por todas as mulheres.

Frisa-se que ainda não há como mensurar o exato alcance dos danos aos fetos em desenvolvimento, pois são seres em formação que não possuem o mesmo sistema biológico da mãe, não podendo em momento algum serem colocados no mesmo patamar de proteção. Afinal, os EPIs que protegem a trabalhadora gestante não são suficientes para a proteção do nascituro, repisando a justificativa do afastamento dessa do ambiente exposto a riscos químicos, físicos e biológicos. 


\section{REFERÊNCIAS BIBLIOGRÁFICAS}

ARANTES, Otília. VAINER, Carlos. MARICATO, Ermínia. A cidade do pensamento único. Petrópolis: Vozes, 2000.

BARCELlOS, Ana Paula de. A eficácia jurídica dos princípios constitucionais: O princípio da dignidade da pessoa humana. 3. ed. rev. atual. Rio de Janeiro: Renovar, 2011.

BARROS, Alice Monteiro de Barros. A mulher e o Direito do Trabalho. São Paulo: LTr, 1995.

BOMFIM, Vólia. Breves Comentários às principais alterações proposta pela reforma trabalhista. Disponível em: <http://genjuridico.com.br/2017/05/09/breves-comentariosprincipais-alteracoes-propostas-pela-reforma-trabalhista> Acesso em 17/01/2019.

BRASIL. Constituição: República Federativa do Brasil de 1988. Disponível em: <http://www.planalto.gov.br/ccivil_03/constituicao/constituicao.htm>. Acesso em 15/01/2019

BRASIL. Constituição: República Federativa do Brasil de 1934. Disponível em: < http://www.planalto.gov.br/ccivil_03/Constituicao/Constituicao34.htm> Acesso em $15 / 01 / 2019$.

CANOTILHO, José Joaquim Gomes. Direito constitucional. 7. ed., Coimbra: Almedina, 2003.

COMPARATO, Fábio Konder. Afirmação histórica dos direitos humanos. 2.ed., rev. e ampl. São Paulo: Saraiva, 2001.

DECRETO - $\quad$ LEI n. 16.300/1923: Disponível em: <http://www.planalto.gov.br/ccivil_03/decreto/1910-1929/D16300.htm.> Acesso em 17/01/2019.

DECRETO -LEI n. 21.417-A/1932: Disponível em: http://www2.camara.leg.br/legin/fed/decret/1930-1939/decreto-21417-17-maio-1932-559563publicacaooriginal-81852-pe.html Acesso em 14/01/2019.

DECRETO - $\quad$ LEI n. 75.207/1975: Disponível em: http://www2.camara.leg.br/legin/fed/decret/1970-1979/decreto-75207-10-janeiro-1975423819-publicacaooriginal-1-pe.html> Acesso em 12/01/2019. 
JUNIOR, Cleber Nilson Amorim. Segurança e saúde no trabalho: princípios norteadores. São Paulo: LTr, 2013.

Le congé maternité - Durée, calcul et indemnités $<$ https://droitfinances.commentcamarche.com/contents/1457-le-conge-maternite-duree-calcul-etindemnites>. Acesso em 16/01/2019.

LEI 9.799/1999: Disponível em: http://www.planalto.gov.br/ccivil_03/LEIS/L9799.htm Acesso em 08/01/2019.

MAGALHÃES, José Luiz Quadros de. Direito Constitucional. Belo Horizonte: Mandamentos, 2000.

MAIA, Katy; LIRA, Sachiko Araki. A mulher no mercado de trabalho. IPEA, 2004).

MENDES, Gilmar Ferreira; BRANCO, Paulo Gustavo Gonet. Curso de Direito Constitucional. Brasília: Saraiva, 2013.

MORAES, Alexandre de. Direitos humanos fundamentais. 2.ed. São Paulo: Atlas, 1998.

PIOVESAN, Flávia. Temas de direitos humanos. 4.ed. São Paulo: Saraiva, 2010.

SARLET, Ingo Wolfgang. A eficácia dos Direitos Fundamentais: uma teoria geral dos direitos fundamentais na perspectiva constitucional. 10.ed. Livraria do advogado Editora: Porto Alegre, 2009.

OIT. Organização Internacional do Trabalho. Disponível em: <https://www.ilo.org/brasilia/lang--es/index.htm>. Acesso em 17/01/2019.

SELANDER, Jenny; ALBIN, Maria; ROSENNHALL, Ulf; RYLANDER, Lars; LEWNW, Marir; GUSTAVSSON, Per. Maternal Occupational Exposure to Noise during Pregnancy and Hearing Dysfunction in Children: A Nationwide Prospective Cohort Study in Sweden, 2015. Disponível em:< https://www.ncbi.nlm.nih.gov/pmc/articles/PMC4892921/>. Acesso em 17/01/2019.

SUSSEKIND, Arnaldo. Curso de direito do trabalho. 3. ed. rev. e atualiz. Rio de Janeiro: Renovar, 2010.

WEIS, Carlos. Direitos Humanos contemporâneio. 3. ed. rev e aum. São Paulo: Malherios, 2014. 


\title{
ANALYSIS OF THE COMPATIBILITY BETWEEN THE INCLUSION OF ARTICLE 394-A IN THE CONSOLIDATION OF LABOR LAWS BY LAW N. 13.467/2017 AND THE INTERNATIONAL PROTECTION OF PREGNANT WORKER
}

\begin{abstract}
The article aims to point out how Law 13.467/2017 brought a great social retrogression regarding the subjection of this research, as well as faced constitucional principles and international human rights treats, as it demages the dignity of the human person. This is because the permission of the pregnant woman in a unhealthy work environment, a situation prohibited by Law 13.287/2016, poses numerous risks not only to the worker, but also to the child. Thus a historical approach was taken to the begenning of human rights norms at the international and national levels up to the present day, using theorical research techniques, with a predominance of consultation with legal sources such as legislation, doctrines and articles legalscientific.
\end{abstract}

Key words: work environment, unhealthy, pregnant, social retrogression, labor reform. 